\title{
Lokale netwerken als instrument voor centraal beleid?
}

\section{De relativiteit van metagovernance*}

\author{
Filip De Rynck, Caroline Temmerman \& Joris Voets
}

\begin{abstract}
Samenwerking tussen publieke actoren en maatschappelijke partners wordt steeds belangrijker als bestuurlijke oplossing voor complexe maatschappelijke uitdagingen in onder andere gezondheidszorg, ruimtelijke ontwikkeling, mobiliteitsbeheersing of waterbeheer. In dit artikel focussen we op de relatie tussen de centrale Vlaamse overheid en lokale netwerken die door deze overheid worden ingericht. In de wetenschappelijke literatuur is veel aandacht voor het begrip metagovernance als analytische bril om de relatie tussen de overheid en netwerken te analyseren. Het begrip houdt de overheid een toolbox voor met rollen en instrumenten waaruit ze kan kiezen om netwerken te ondersteunen en te stimuleren om zo tot de gewenste netwerkresultaten te komen. Ons onderzoek toont echter aan dat zo'n benadering niet volstaat om de relatie tussen de centrale overheid en lokale gemandateerde netwerken in Vlaanderen te vatten. We pleiten voor een bredere invulling van het begrip metagovernance, waarbij de dynamiek van lokale netwerken wordt bekeken als de uitkomst van machtsrelaties tussen actoren die zowel op lokaal als op centraal niveau vertegenwoordigd zijn en onderling met elkaar verweven zijn. Pas op die manier begrijpen we waarom bepaalde keuzes over lokale gemandateerde netwerken tot stand komen, waarom lokale netwerken een gebrek aan dynamiek vertonen en waarom lokale actoren in lokale netwerken ook niet willen dat lokale netwerken dynamischer en effectiever zouden worden. We merken wel dat de druk op deze arrangementen toeneemt, onder andere door nieuwe actoren die niet bij deze arrangementen betrokken zijn.
\end{abstract}

\section{Inleiding}

In literatuur over lokale netwerken domineert het beeld van de spontane samenwerking tussen organisaties, waarbij zij er vrijwillig voor kiezen om samen te werken vanuit een vaak nog te ontwikkelen onderlinge afhankelijkheid (Hardy et al., 2003; Phillips et al., 2000). In de literatuur komen dan aspecten als management, leiderschap, vertrouwen en de verdeling van middelen tussen de netwerkpartners aan bod (zie bijvoorbeeld Agranoff \& McGuire, 2003). Als voor dat soort netwerken sprake is van 'metagovernance', wordt bekeken welke rollen de overheid ten

* $\quad$ Alle drie auteurs zijn verbonden aan de Universiteit Gent. 
aanzien van dergelijke spontaan gegroeide netwerken vervult (Sørensen \& Torfing, 2009; Torfing et al., 2012). Heel wat lokale samenwerkingsverbanden in de publieke sector ontstaan echter niet vrijwillig. Ze worden door een centrale overheid bedacht en vervolgens als een beleidsinstrument van die overheid uitgerold (Popp \& Casebeer, 2015). Het denken in netwerken als overheidsinstrument is ondertussen immers erg populair, in Vlaanderen en in Nederland. De centrale overheid bepaalt dan onder andere de doelstellingen van de lokale netwerken, de samenstelling, de organisatievorm en de financieringsvoorwaarden. In de verhouding tussen de mandaterende centrale overheid en het gemandateerde lokale netwerk kan veel variatie zijn: tussen sterk aangestuurde en aan voorwaarden gebonden lokale netwerken of heel erg grote vrijheidsgraden voor de lokale netwerkpartners. De metagovernance is complexer dan bij de spontane autonome lokale netwerken, omdat het gaat over netwerkconstructies die door de overheid zelf worden bedacht en vormgegeven en omdat het lokale netwerk gevat zit in centraal-lokale verhoudingen tussen actoren waardoor ze ook een deel zijn van het debat over centralisatie versus decentralisatie. Een laatste complexiteit is dat het niet over een een-op-een verhouding gaat (een overheid versus een netwerk), maar over een centrale overheid die meestal een groot aantal gemandateerde lokale netwerken van hetzelfde type uitrolt over heel haar werkgebied. De dynamieken in en tussen deze lokale netwerken kunnen theoretisch sterk verschillen, afhankelijk van de lokale contexten. De vraag is dan hoe de centrale overheid in haar metagovernance-keuzes omgaat met die differentiatie.

De leidende gedachte in deze bijdrage is dat de beleidskeuzes die een centrale overheid maakt ten aanzien van door haar opgerichte lokale netwerken, sterk worden mede bepaald door de manier waarop actoren die in de lokale netwerken actief zijn, hun relaties op het centrale niveau gebruiken. Dat betekent dat we de keuzes inzake metagovernance moeten inbedden in de machtsverhoudingen die zich rond deze gemandateerde netwerken ontwikkelen. Met macht bedoelen we de wijze waarop actoren hun machtsbronnen in of ten aanzien van lokale netwerken aanwenden.

\section{Metagovernance in centraal-lokale verhoudingen}

Het concept metagovernance wordt in empirisch onderzoek vaak gebruikt om de positie van de overheid ten aanzien van netwerken te bestuderen (zie o.a. Whitehead, 2003; Kelly, 2006; Bell \& Park, 2006; Mosely \& James, 2008; Doberstein, 2013; Thuesen, 2013; Temmerman et al., 2015). Sørensen en Torfing (2009) onderscheiden vier metagovernance-rollen voor de overheid: ontwerper, kadersteller, manager en actor. De rollen van ontwerper en kadersteller omschrijven zij als hands-off vormen. Management en participatie als actor in het netwerk zijn sterkere vormen om het netwerk te beïnvloeden, via directe interactie tussen de metagovernor en het netwerk (hands-on). Volgens deze auteurs kan de overheid door het maken van een rationele afweging tussen deze rollen een bijdrage leveren aan de effectiviteit en de democratische kwaliteit van netwerken. In deze literatuur domineert het beeld van netwerken als vrijwillige samenwerkingsverban- 
den waarbij op basis van vertrouwen en gelijkheid op zoek wordt gegaan naar oplossingen voor complexe problematieken. Voor de overheid is een belangrijke rol weggelegd in het scheppen van de nodige condities voor de samenwerking, waarbij ze evenwel respect moet tonen voor het zelfregulerende karakter van het netwerk. Volgens de inzichten van metagovernance impliceert dit dat de overheid zich moet onthouden van hiërarchische sturingsmechanismen, ten voordele van meer indirecte manieren om de samenwerking te faciliteren, te ondersteunen en te stimuleren. Een te sterk regulerende overheid plaatst de netwerken in de schaduw van de hiërarchie (Doberstein, 2013; Whitehead, 2003).

We gaan niet in op de kritiek dat de impact van de (regelgevende) overheid ook in spontaan gegroeide netwerken in de praktijk vaak veel groter is dan de premisse van zelfsturing doet vermoeden (voor een synthese van deze kritieken zie o.a. 6, 2015). In gemandateerde lokale netwerken binnen een centraal-lokale verhouding is de hiërarchie per definitie aanwezig omdat het de centrale overheid is die lokale samenwerking in netwerkvorm oplegt en in dat mandaat bepaalt waartoe dat netwerk moet dienen. Deze setting roept volgens Popp en Casebeer (2015) vervolgens specifieke problemen op: de weerstand van de lokale actoren om zich ook effectief te engageren, zeker als de netwerking een verplichting is; het gevaar van een te uniforme en centraal aangestuurde benadering; het risico van window dressing waarbij de overheid netwerken installeert omdat dit nu eenmaal zo hoort en past in de beleidsretoriek, maar ze niet voorziet van de nodige middelen om de opgelegde doelstellingen waar te maken.

Voor onze analyse van de verhouding tussen de centrale Vlaamse overheid en door haar gemandateerde lokale netwerken sluiten we ons aan bij de benadering van Laffin (2009), die stelt dat 'central-local relations can be understood as an arena in which many actors behave strategically within a system which offers a range of possible locations to pursue their objectives' (p. 23). Figuur 1 stelt schematisch voor hoe wij naar deze arena kijken. We zien hoe er relaties ontstaan tussen de centrale overheid en de lokale overheden; tussen lokale overheden en lokale maatschappelijke organisaties. We zien vooral hoe de lokale organisaties vaak deel uitmaken van grote organisaties die op Vlaams niveau vertegenwoordigd zijn en op dat niveau intense relaties uitbouwen met de ministers, hun kabinetten en hun administraties op het centrale Vlaamse niveau. 
Figuur 1 Lokale gemandateerde netwerken in centraal-lokale relaties

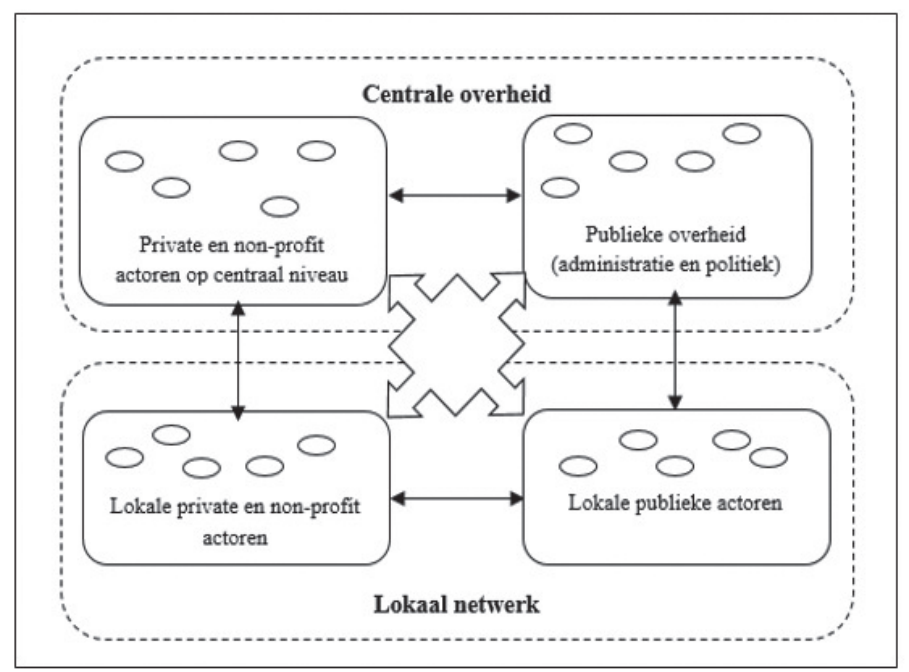

\section{Methoden}

We analyseerden twee typen lokale gemandateerde netwerken die door de Vlaamse overheid in heel Vlaanderen werden opgelegd. Het gaat vooreerst over de Samenwerkingsinitiatieven Eerstelijnsgezondheidszorg (SEL), dat een 'door de Vlaamse Regering erkend samenwerkingsverband is van vertegenwoordigers van zorgaanbieders en eventueel van vertegenwoordigers van mantelzorgers en gebruikers en/of vrijwilligers, dat gericht is op het optimaliseren van de zorg binnen een bepaald geografisch afgebakend werkgebied' (Decreet Eerstelijnsgezondheidszorg, Art. $\left.2,11^{\circ}\right) .{ }^{1}$ De basisregels voor de aansturing van het netwerk liggen vervat in het Decreet Eerstelijnsgezondheidszorg (2004) en het Uitvoeringsbesluit (2008). ${ }^{2}$ Het SEL is sinds 2010 de opvolger van de vroegere Samenwerkingsinitiatieven voor Thuiszorg (SIT), een bottom-up netwerk van zorgaanbieders inzake thuiszorg.

De regionale netwerken voor socio-economische streekontwikkeling vormen het tweede netwerk. Het Regionaal Sociaaleconomisch Overlegcomité (RESOC) organiseerde het gebiedsgebonden tripartiete overleg tussen de sociale partners, provincies en gemeenten. De werking van de RESOC's was gekaderd binnen het

1 Decreet van 3 maart 2004 betreffende de eerstelijnsgezondheidszorg en de samenwerking tussen de zorgaanbieders (Belgisch Staatsblad 20 april 2004).

2 Besluit van de Vlaamse Regering van 19 december 2008 betreffende de Samenwerkingsinitiatieven Eerstelijnsgezondheidszorg (Belgisch Staatsblad 31 maart 2009). 
Decreet van 7 mei 2004. ${ }^{3,4}$ De Vlaamse overheid is aanwezig op het terrein via een van haar verzelfstandigde agentschap (zbo in Nederland), de Vlaamse Dienst voor Arbeidsbemiddeling en Beroepsopleiding (VDAB). Net zoals de SEL's kenden de RESOC's een voorloper in de Streekplatformen, die van onderuit waren gegroeid en niet overal in Vlaanderen actief waren. We bestudeerden het functioneren van deze twee netwerken tot 2015 (en de evolutie in de jaren ervoor) in drie regio's: de grootstedelijke Gentse regio, de kleinstedelijke regio Zuid-WestVlaanderen en de landelijke regio rond Turnhout. We analyseerden documenten en interviewden 64 lokale en Vlaamse sleutelfiguren. Voor elk van de zes lokale netwerken zijn zes tot acht sleutelpersonen bevraagd, uit een mix van soorten organisaties en functies in het netwerk. We gebruikten een gestructureerde vragenlijst en legden alle respondenten ook dezelfde stellingen voor over de kwaliteit van de lokale netwerking. Daarnaast werden ambtenaren op het Vlaamse niveau bevraagd en sleutelfiguren uit de besturen van de centrale non-profitorganisaties waarvan de lokale afdelingen actief zijn in de lokale netwerken.

\section{Resultaten}

We onderzochten hoe actoren in de lokale netwerken de impact inschatten van het regelgevende kader waarmee de Vlaamse overheid deze lokale netwerken heeft gemaakt, de manier waarop ze deze ondersteunt en evalueert. De impact van dat kader onderzochten we op basis van de zes variabelen van Bell en Hindmoor (2009), die deze gebruikten om de relatie tussen de centrale overheid en lokale opgelegde netwerken te analyseren. We gingen na in welke mate deze variabelen de effectiviteit van de lokale netwerken helpen verklaren.

\section{Regulering}

Voor beide soorten netwerken is sprake van een uniform beleidskader dat op een gebiedsdekkende manier wordt uitgerold over de verschillende regio's in Vlaanderen. De regelgeving omvat in beide cases richtlijnen met betrekking tot het van bovenaf opgelegde werkingsgebied, de verplichte deelname van partners, het mandaat en de doelstellingen van het lokale netwerk. De analyse toont aan dat de impact van het opleggen van de schaal voor de netwerken en de verplichte samenstelling samenhangen met de mate waarin dat uniforme beleidskader aansloot bij de eigen keuzes binnen het vroegere spontane netwerk. In de regio Gent gingen de hervormingen van de beide netwerken gepaard met grote veranderingen in het werkgebied en de samenstelling van het netwerk. Mede hierdoor verliep de overgang zeer moeizaam en waren er veel discussies tussen de partners. Deze negatieve ervaringen werken door tot op vandaag en leiden tot heel weinig effectieve samenwerking. In de regio's Kempen en Zuid-West-Vlaanderen was de impact van

3 Decreet van 7 mei 2004 betreffende het statuut, de werking, de taken en de bevoegdheden van de erkende regionale samenwerkingsverbanden, de sociaaleconomische raden van de regio en de regionale sociaaleconomische overlegcomités (Belgisch Staatsblad 9 juni 2004).

4 De RESOC-SERR-werking werd opgeheven door de Conceptnota Versterkt Streekbeleid van 17 juli 2015. 
de opgelegde hervormingen tamelijk beperkt omdat het zelf gekozen werkgebied en de opgelegde schaal nauw aansloten bij het eerder zelf gekozen gebied en omdat bijna alle verplichte partners reeds deel uitmaakten van het vroegere bottom-up netwerk.

\section{Effectiviteit en verantwoording}

Het opvolgen van de effectieve uitvoering van de verplichte opdrachten gebeurt in beide netwerken aan de hand van een jaarlijkse rapportering aan de Vlaamse administratie. De controle vanuit de Vlaamse overheid is echter zeer beperkt. Dit komt omdat in de regelgeving geen concrete outputs of indicatoren over de effectiviteit van de lokale netwerken opgenomen zijn waarop de administratie zich kan beroepen om haar beoordeling op te baseren. Daarnaast is er in beide cases sprake van een gebrek aan personeelscapaciteit bij de administratie en van een geringe belangstelling bij de politieke verantwoordelijken. Van een noemenswaardige opvolging en centraal leiderschap is dus geen sprake. Het gebrek aan opvolging en zelfs belangstelling voor de lokale netwerken betekent ook dat de lokale partners zelf kunnen kiezen welke van de opgelegde taken ze opnemen en hoe ze hier invulling aan geven. Lokale netwerken zouden zelf ambities kunnen ontwikkelen voor de samenwerking. Er wordt hen, ook door het gebrek aan opvolging en evaluatie, weinig in de weg gelegd.

\section{Financiering}

In beide netwerken stelt de Vlaamse overheid middelen ter beschikking voor het werven van personeel en hiermee samenhangend het uitvoeren van de verplichte opdrachten. De subsidies worden telkens toegekend via een systeem van inputfinanciering, gebaseerd op bepaalde objectieve criteria. Door deze keuze heeft de Vlaamse overheid geen mogelijkheid om het engagement van de lokale netwerkpartners af te dwingen. Ook de partners zelf worden hierdoor niet gestimuleerd om zich voor de effectiviteit van het netwerk in te zetten, omdat de middelen toch jaarlijks toegekend worden. De enige voorwaarde is het jaarlijks indienen van een financieel en een inhoudelijk verslag. Ook die controle is niet meer dan een bureaucratische formaliteit. De Vlaamse overheid controleert zeker niet op basis van outputcriteria: in principe hebben de lokale actoren dus een grote vrijheid om hun eigen effectiviteit in te vullen en te versterken.

De functies democratisch gehalte (de mogelijkheid van de overheid om in te grijpen in het besluitvormingsproces van het netwerk) en legitimiteit (waarbij de overheid toeziet op de transparantie en eerlijkheid van het samenwerkingsproces) zijn in deze cases minder essentieel omdat we vaststelden dat het opgelegde niveau van samenwerking binnen het lokale netwerk beperkt was tot afstemming en overleg. Het zijn twee netwerken die zich beperken tot coördinatie en die nauwelijks tot gemeenschappelijke netwerk-gedreven collaboratie komen, zij het dat er tussen de drie regio's wel wat variatie is. Maar die variatie is niet zo extreem: in geen enkel geval neemt het netwerk beslissingen die bindend zijn voor de partners en waarbij het engagement van de partners kan worden afgedwongen. Of dat wenselijk of gunstig zou zijn, laten we hier buiten beschouwing. De Vlaamse overheid legt op geen enkele manier verplichtingen op. De Vlaamse overheid verbiedt 
via haar regelgeving de lokale dynamiek en verdergaande samenwerking niet: lokale netwerken die dat zouden willen, zouden op eigen kracht tot sterkere netwerking kunnen komen, maar dat gebeurt dus niet. In het vervolg van de analyse tonen we dat de lokale actoren zelf een meer collaboratieve netwerking niet willen. Dat heeft niet veel te maken met de impact van het regelgevende kader dat de organisatie en werking van de lokale netwerken regelt, maar wel met de machtsverhoudingen die zich in de centraal-lokale relaties ontwikkelen.

\section{Macht en beïnvloeding in de centraal-lokale relaties}

In beide cases zien we de doorwerking van de macht van bepaalde groepen uit het georganiseerde middenveld, die nauw verweven zijn met de centrale Vlaamse beleidsvoerders. Macht vatten we in een netwerkperspectief op als de wijze waarop actoren in het netwerk hun hulpbronnen gebruiken om hun zienswijze op het lokale netwerk en de agenda van het lokale netwerk vanuit hun organisatiebelangen te bepalen, eventueel te domineren. We merkten dat de ziekenfondsen de dominante actoren zijn in het domein van gezondheidszorg en de sociale partners (werkgevers- en vakorganisaties) in het domein van werk en sociale economie. De macht van deze organisaties heeft zijn wortels in het Belgische en nu ook Vlaamse neocorporatisme, waarmee we duiden op de manier waarop deze maatschappelijke organisaties in het medebeheer van allerlei publieke instellingen en dienstverlening zijn opgenomen, een proces met sterke historische wortels dat tot op vandaag zorgt voor een intense verwevenheid tussen politieke vertegenwoordigers en middenveldorganisaties met dezelfde levensbeschouwing en een sterke invloed en macht van deze organisaties in de politieke besluitvorming. Daar vinden we de centrale verklaring voor de zwakke netwerkvorming op lokaal niveau. We illustreren deze vaststelling.

De ziekenfondsen konden, in de periode van de opmaak van de regelgeving voor de netwerken inzake gezondheidzorg, een sterke invloed uitoefenen op de afbakening van het werkingsgebied van het lokale netwerk. Zo bepaalt het uitvoeringsbesluit dat een SEL moet worden geënt op de veertien verzorgingsgebieden van de grotere Vlaamse steden uit het Zorgregiodecreet (2003) in plaats van de 68 zorgregio's voor de kleine steden. De ziekenfondsen waren een voorstander van de grotere schaal omdat dit aansluit bij het werkingsgebied van de eigen organisatie. Een aantal andere partners, waaronder de huisartsen, waren voorstander van een kleinere schaal, omdat hun werking sterk lokaal verankerd is. Zij hebben het niet gehaald.

Ook de aanstelling van een huisarts als voorzitter of ondervoorzitter van het lokale netwerk werd door de ziekenfondsen beïnvloed. Hierdoor kunnen zij ook een voorzitter leveren en niet enkel de huisartsen, zoals initieel voorzien was in het voorstel van de administratie. In het RESOC konden de sociale partners hun agenda opdringen inzake de voorwaarden met betrekking tot de vormgeving en de positie van de nieuwe structuren voor streekontwikkeling. De sociale partners toonden zich met name een sterke pleitbezorger van een samenstelling die nagenoeg een kopie was van de overlegstructuren op Vlaams niveau. Dit is een onderdeel van een bredere strategie van de sociale partners om hun verplichte vertegenwoordiging en hun onderlinge verhoudingen in overlegstructuren op de ver- 
schillende bestuursniveaus te bewaken en die verhoudingen op alle niveaus op te leggen (regionaal - provinciaal - Vlaams - federaal).

In de twee lokale netwerken is er een intense verwevenheid tussen actoren op het centrale en het lokale niveau en tussen de centrale organisaties en de Vlaamse regering. We stellen in beide cases vast dat elke lokale netwerkpartner, via hun centrale organisaties, toegang zoekt tot de beleidsmakers op centraal niveau om zo te proberen de beleidskeuzes met betrekking tot het lokale netwerk te beïnvloeden. Zowel in het SEL als in het RESOC zien we dat de eerdergenoemde middenveldorganisaties die deel uitmaken van het lokale netwerk, ook deel uitmaken van de besluitvorming op Vlaams niveau over de beleidsmateries waarvoor de lokale netwerken werden geïnstalleerd. Over de schaal, de organisatorische vormgeving, de samenstelling, de inhoud en de reikwijdte van de lokale netwerken wordt op centraal niveau onderhandeld en het zijn eerder de belangen van de centrale organisaties die daarbij domineren. Zij onderhandelen over de vormgeving van de lokale netwerken in naam van hun lokale afdelingen en doen dat rechtstreeks met de minister en zijn kabinet, waarin zij vaak hun vertegenwoordigers hebben. Zij bepalen in deze onderhandelingen over de regelgeving voor de lokale netwerken hoe ver de lokale netwerken in de samenwerking mogen gaan en zij beslissen op deze manier meteen ook over de rol die hun lokale organisaties in die lokale netwerken wel of niet mogen spelen. De lokale netwerken maken zo integraal deel uit van de centraal aangestuurde bestuurlijke arrangementen inzake gezondheidszorg, economie en arbeidsmarkt. Ook de zelfstandige medici en de publieke partners in de lokale netwerken hebben een aantal toegangskanalen tot de centrale politieke overheid uitgebouwd via hun respectievelijke koepel- en belangenorganisaties. De Vlaamse Vereniging van Steden en Gemeenten (VVSG, de VNG in Nederland) treedt op als vertegenwoordiger van de lokale besturen en OCMW's. Domus Medica vzw is de belangenbehartiger van de huisartsen en huisartsenkringen in Vlaanderen. Hun machtspositie op centraal niveau is echter veel kleiner, hun relaties met de besluitvormers zijn veel minder invloedrijk en hun impact op 'hun' lokale actoren is veel beperkter dan dat het geval is bij de grote en sterk centraal georganiseerde middenveldorganisaties.

Onze analyse hield ook rekening met de tijdsfactor: we vroegen onze geïnterviewden hoe de machtsverhoudingen in het netwerk doorheen de tijd eventueel evolueerden. Twee evoluties vielen op. Vooreerst verdedigen de afzonderlijke ziekenfondsen zeker nog hun eigen belangen maar de grenzen tussen de ziekenfondsen worden ook meer poreus. Naarmate nieuwe actoren actiever worden en zich als actor in lokale netwerken opdringen, werken de drie traditionele ziekenfondsen (katholiek, liberaal en socialistisch) ook meer samen om de belangen van de ziekenfondsen als groep te verdedigen. Dat doen ze door gemeenschappelijke standpunten uit te werken over de positie van de ziekenfondsen in de lokale netwerken.

Ten tweede: binnen de ziekenfondsen zien we een voorzichtige evolutie naar meer autonomie voor de lokale vertegenwoordigers. $\mathrm{Zij}$ proberen binnen hun eigen organisatie meer ruimte te verwerven om binnen de lokale netwerken meer autonome beslissingen te nemen over samenwerking met andere partners. Deze evoluties gaan samen met de opkomst van andere koepel- en belangenorganisa- 
ties, bijvoorbeeld de patiëntenverenigingen, die een nog relatief bescheiden vorm van tegenmacht opbouwen. Zij eisen ook hun plaats op in de lokale netwerken en stellen de in- en uitsluiting ter discussie die met dit soort opgelegde en centraal onderhandelde netwerken gepaard gaat. Ze zetten ook druk op de monopolies van de ziekenhuizen, die niet meer alleen namens de patiënten spreken. De groei en de grotere assertiviteit van deze zelforganisaties zetten druk op de traditionele posities en verhoudingen en verhogen de druk op de lokale afdelingen van de ziekenfondsen.

Ook op het domein van werk en sociale economie lijkt het historisch gegroeide en centraal aangestuurde sociaal overlegmodel steeds meer onder druk te komen en zien we identieke patronen. Critici geven aan dat het overlegmodel niet meer beantwoordt aan de huidige sociaaleconomische realiteit. Ook deze organisaties hebben steeds meer te maken met enerzijds nieuwe tegenspelers die zich meer autonoom organiseren, en anderzijds lokale afdelingen van de werkgevers- en werknemersorganisaties die meer ruimte opeisen voor hun eigen lokale doelstellingen. Het centralistisch aangestuurde overlegmodel werkt ook steeds minder goed: de consensus waarop akkoorden eertijds steunden, lijkt af te brokkelen. De sociale partners hebben het moeilijk om op centraal niveau nog tot gedragen akkoorden te komen, waardoor er meer ruimte komt voor lokaal initiatief. Ook in de drie onderzochte regio's geven de netwerkcoördinatoren en de sociale partners zelf aan dat de werkgevers- en werknemersorganisaties er nog maar moeilijk in slagen om overleg te plegen en afstemming te vinden rond thema's in het arbeidsmarktbeleid. De legitimiteit van de lokale netwerken als onderdeel van de centraal onderhandelde akkoorden neemt af en de druk om de lokale netwerken meer open te stellen voor nieuwe spelers neemt toe. Allerlei lokaal gegroeide organisaties die met specifieke doelgroepen werken en voor hun belangen opkomen, dringen zich op en hebben hulpbronnen die voor de lokale netwerking essentieel zijn (kennis en contacten met doelgroepen, specifieke expertise inzake bijvoorbeeld het werken met vluchtelingen).

\section{Reflectie en conclusie}

De analyse toonde dat de centrale Vlaamse overheid weinig verwacht van deze beide soorten lokale netwerken en deze weinig actief aanstuurt of opvolgt. Er zijn nauwelijks impulsen voor samenwerking, zoals ook blijkt uit de aard van de financiering. De Vlaamse overheid legt wel de werkgebieden op, bepaalt de samenstelling en omschrijft de opdrachten van deze lokale netwerken die overwegend in de sfeer van de coördinatie te situeren zijn. De bredere politicologische analyse toonde evenwel dat deze keuzes zelf het gevolg zijn van de machtsverhoudingen tussen de centrale organisaties die met elkaar en met de politici onderhandelen over de vormgeving van de lokale netwerken. Bij alle cruciale kenmerken van de lokale netwerken (gebiedsafbakening, opname van actoren, dagelijkse werking, wijze van financiering, enzovoort) zijn de centraal onderhandelde akkoorden doorslaggevend geweest voor de vormgeving van de netwerken. Die akkoorden over de lokale netwerken zijn dus ingebed in centrale arrangementen en vloeien 
voort uit machtsverhoudingen op centraal niveau en uit de verwevenheid van centrale actoren met de Vlaamse beleidsmakers. Ze zijn niet op de eerste plaats bedacht om in te spelen op de lokale dynamiek tussen lokale organisaties. Het gebrek aan dynamiek tussen de lokale organisaties maakt evenwel zelf deel uit van deze onderhandelde akkoorden: de lokale organisaties mogen niet verder gaan, als ze dat al zouden willen, dan wat hun centrale vertegenwoordigers met elkaar over de reikwijdte van deze lokale netwerken hebben afgesproken. Deze akkoorden komen uit een periode van een dominant neocorporatistisch beleid, gebaseerd op vaste verhoudingen op centraal niveau. Het lokale niveau en de relaties tussen lokale actoren makten integraal deel uit van de neocorporatistische arrangementen. We zien hoe dat model stilaan afbrokkelt, als gevolg van de opkomst van nieuwe spelers, als gevolg van de verminderde effectiviteit en de daarmee verbonden verminderde legitimiteit van de klassieke centrale overlegstructuren tussen de traditionele partners. Dat zet druk op de lokale netwerken: nieuwe spelers kloppen aan en de klassieke spelers voelen de verhoogde druk om hun eigen legitimiteit in de lokale netwerken meer op eigen kracht te bewijzen. Op dit moment is die evolutie evenwel nog niet krachtig genoeg om de samenwerking op een meer autonoom lokaal bepaalde wijze sterker te maken.

Uit onze analyse blijkt dat de kritiek dat de creatie van lokale gemandateerde netwerken door de centrale Vlaamse overheid een vorm van 'window dressing' is, terecht is. Het is echter veel te eenvoudig om dit enkel toe te wijzen aan een oppervlakkige omarming van het modieuze concept van 'netwerken' om daar snel politiek mee te scoren. Er is veel meer aan de hand: de lokale netwerken mogen niet te actief zijn en mogen niet te veel eigen dynamiek vertonen. Het gaat hier niet om een voorspelbare klacht van lokale actoren die toch zo dynamisch willen zijn, maar door een centrale overheid helaas vanuit haar centralistische drang en dwang in hun anders onstuitbare dynamiek geboycot worden. Lokale actoren maken integraal deel uit van een strategisch spel om de lokale netwerken niet te dynamisch te laten worden omdat deze anders de verhoudingen tussen de centrale spelers dreigen te verstoren.

We hebben aangegeven dat het concept metagovernance in literatuur over spontaan gegroeide netwerken op een tamelijk instrumenteel perspectief steunt: hoe verhoudt de overheid zich tot deze netwerken en welke keuzes maakt ze in haar verhouding? Het is een open vraag of deze instrumentele focus stand zou houden bij analyse, zoals in deze bijdrage, van de verwevenheid die zich ongetwijfeld ook in spontane lokale netwerken ontwikkelt tussen vertegenwoordigers van actoren in het netwerk en politici en ambtenaren die dan de overheid vertegenwoordigen. Voor de gemandateerde lokale netwerken die wij in de Vlaamse context analyseerden, is deze focus alvast helemaal ontoereikend. Om te begrijpen waarom bepaalde keuzes over de werking van lokale netwerken tot stand komen, moeten we de verhoudingen tussen de lokale actoren plaatsen in het bredere complex van centraal-lokale machtsverhoudingen, ook en vooral tussen de centrale actoren. De afstandelijkheid van de overheid ten opzichte van de lokale netwerken, die door het concept metagovernance wordt gesuggereerd, is hier helemaal niet aanwezig. Voor zover het concept dan nog zin heeft, wijst metagovernance eerder op de onderhandelde positie die de overheid inneemt of moet innemen als gevolg van 
de arrangementen die tussen centrale spelers worden afgesloten en waar lokale actoren in lokale netwerken een integraal deel van zijn. Omdat deze arrangementen echter ook als gevolg van maatschappelijke evoluties en kritiek op traditionele netwerken onder druk komen te staan van nieuwe spelers en nieuwe thema's, zou metagovernance kunnen wijzen op de ruimte die eventueel vrijkomt om lokale netwerken meer ruimte en kansen te geven. Onze analyse leert dat dit dan weer het gevolg zal zijn van veranderende onderhandelingsverhoudingen en niet tot stand zal komen als gevolg van autonome keuzes die een overheid op afstand van lokale netwerken maakt, zoals het begrip metagovernance suggereert.

\section{Literatuur}

6, P. (2015). Governance: if governance is everything, maybe it's nothing. In A. Massey \& K. Johnston (Eds.), The international handbook of public administration and governance (p. 56-80). Cheltenham: Edward Elgar Publishing.

Agranoff, R., \& McGuire, M. (2003). Inside the matrix: Integrating the paradigms of intergovernmental and network management. International Journal of Public Administration, 26(12), 1401-1422.

Bell, S., \& Hindmoor, A. (2009). Rethinking governance: The centrality of the state in modern society. Cambridge University Press.

Bell, S., \& Park, A. (2006). The problematic metagovernance of networks: Water reform in New South Wales. Journal of Public Policy, 26, 63-83.

Doberstein, C. (2013). Metagovernance of urban governance networks in Canada: in pursuit of legitimacy and accountability. Canadian Public Administration, 56(4), 584-609.

Hardy, C., Phillips, N., \& Lawrence, T.B. (2003). Resources, knowledge and influence: The organizational effects of interorganizational collaboration. Journal of Management Studies, 40(2), 321-347.

Kelly, J. (2006). Central regulation of English local authorities: an example of meta-governance? Public Administration, 84(3), 603-622.

Laffin, M. (2009). Central-local relations in an era of governance: Towards a new research agenda. Local Government Studies, 35(1), 21-37.

Mosely, A., \& James, O. (2008). Central state steering of local collaboration: Assessing the impact of tools of meta-governance in homelessness services in England. Public Organization Review, 8, 117-136.

Phillips, N., Lawrence, T.B., \& Hardy, C. (2000). Inter-organizational collaboration and the dynamics of institutional fields. Journal of Management Studies, 37(1), 23-43.

Popp, J.K., \& Casebeer, A. (2015). Be careful what you ask for: Things policy-makers should know before mandating networks. Healthcare Management Forum, 28(6), 230-235.

Sørensen, E., \& Torfing, J. (2009). Making governance networks effective and democratic through metagovernance. Public Administration, 87(2), 234-258.

Temmerman, C., De Rynck F., \& Voets, J. (2015). Opening the black box of metagovernance: The roles of central government in local multilevel networks - the case of the local job centers in Flanders. International Review of Public Administration, 20(3), 227-242.

Thuesen, A.A. (2013). Experiencing multi-level meta-governance. Local Government Studies, 39(4), 600-623. 
Torfing, J., Peters, G., Pierre, J., \& Sørensen, E. (2012). Interactive governance: Advancing the paradigm. Oxford/New York: Oxford University press.

Whitehead, M. (2003). 'In the shadow of hierarchy': Meta-governance, policy reform and urban regeneration in the West Midlands. Area, 35(1), 6-14. 